\title{
Dynamic and Uncertain Pathways between Early Childhood Inclusion Policy and Practice
}

\author{
Esther E. Onaga \\ Tiffany L. Martoccio \\ Michigan State University \\ USA
}

\begin{abstract}
In the United States, early childhood inclusion dates back to the civil rights movement with the 1954 case of Brown v. The Board of Education, an issue of segregation by race in schools and followed by the Americans for Disability Act (ADA). A Free Appropriate Education (FAPE) in the Least Restrictive Environment (LRE), from Individuals with Disabilities Education Act (IDEA) has influenced inclusive practices. Both the IDEA and the No Child Left Behind (NCLB) provide language supporting early childhood inclusion, but the implementation of inclusion has been uneven. Many factors influence practice, including changes overtime in the interpretation of existing laws, definitions of what is inclusion and research outcomes of inclusive practices. Local infrastructure for serving young children, funding, qualified personnel, motivated leadership and teachers, and informed parents are also factors impeding or facilitating early childhood inclusion. The complexity involved suggests a dynamic process with uncertain pathways from policy to practice.
\end{abstract}

Key words: inclusion, policy, USA

Inclusive education for young children has increasingly gained attention with the research evidence of how quality education in the early years can have significant and positive long term effects (Schweinhart, Montie, Xiang, Barnett, Belfield, \& Nores, 2005), and how brain development research suggest the importance of taking the window of opportunity to provide for high quality learning experiences (Chugani \& Bruer, 1998).

But what is inclusion? There is debate about the issue of inclusion versus mainstreaming. Inclusion involves creating situations in the setting that support the needs of the student; mainstreaming children, on

Correspondence concerning this article should be addressed to Esther E. Onaga, Ph.D., 2J Human Ecology, Michigan State University, East Lansing, MI 48824, USA. Electronic mail may be sent to onaga@msu.edu. the other hand, involves having students with disabilities learning to be in a general education setting. According to Salisbury (1991) who examines mainstreaming during the early childhood years, many programs are beginning to mainstream young children with disabilities in a typical educational setting throughout the United States. Therefore, the philosophy of inclusion advocates that children of all abilities grow up together as participating members of our society (Odom, 2000; Guralnick, 2001).

Schwartz and colleagues (2002), however, were clear that there is no single 'right' way to implement inclusion; it depends on the program and the perspectives of the observer and/or participant. This does not mean that 'inclusion' can be all things to all people, but it can be delivered in various ways. Guralnick (2001) described a range of five practice 
options: (a) full inclusion where children with disabilities are full participants in a general early childhood program with specialized services provided within the context of the program, (b) cluster model where a small group of children with disabilities is attached to a regular program but activities and services are provided separately in an area of the classroom, so children participate in some but not all activities together, (c) reverse inclusion differs from the other two programs in that children with disabilities outnumber regularly developing children and includes the provision of special services, (d) social inclusion where children may share the same building, but normally developing children are located in separate rooms and do not join with disabled children in most activities, except during recreation and physical activity periods, and (e) dual enrollment where disabled children are enrolled in a traditional special education class for part of the day and in a regular community-wide, early childhood program such as Head Start, for the remainder of the day and part of the week. This is a different type of option, which provides additional challenges for multi-disciplinary collaboration and communication but is a prevalent model in the U.S.

Studies appear to support the benefits of inclusion experiences for the developing child (Guralnik, 2001; Odom, 2000; Wolery \& Wilbers, 1994). Research shows that children with disabilities learning in inclusive settings show more advanced plan than those learning in 'self-contained' classrooms (Diamond, Hestenes, \& O'Connor, 1994). On developmental measures, children with disabilities perform comparably in inclusive settings as they do in segregated special education settings (Buysse \& Bailey, 1993; Odom \& Diamond, 1998). The attitudes of typically developing children towards children with disabilities appear to be positively affected through inclusion (Peck, Carlson, \& Helmstetter, 1992) and knowledge about disability seems to be increased as well (Diamond \& Hestenes, 1994; Diamond \& Hestenes, 1996). Yet, even with policies in place and these rather positive research findings about inclusion, opportunities for inclusive experiences in early childhood education have not become a reality for many children in the United States. Therefore, this article will describe the federal policies related to early childhood inclusion and show some of the work, which has been done at the state and local levels. It will also address the insufficiency of policies to promote inclusion and the complex factors influencing implementation.

\section{Historical Overview of Policies Promoting Early Childhood Inclusion at Federal Level}

\section{Individuals with Disabilities Education Act}

The history of public and social policy around the inclusion movement began from the civil rights perspective. In 1954, the United States Supreme Court made one of the most judicial turning points with the case of Brown v. the Board of Education, a decision about racial segregation in schools where it was determined that 'separate is not equal'. Another act of Congress influential in supportive inclusive practices is the Americans for Disabilities Act (ADA) of 1990, which provided increased access to community settings and employment. In the context of the civil rights movement, the educational system, along with parental advocacy created a trajectory for creating laws and policies to support education of children with disabilities. Racial inequity was a concern of litigation, thus leading to the first special education legislation, Individuals with Disabilities Education Act (IDEA), which is the latest amendment to the Education of the Handicapped Act (EHA), Public Law (PL) 94-142 in 1975 (Skiba, Simmons, Ritter, Gibb, Rausch, Cuadrado et al., 2008). IDEA includes two basic requirements: a Free Appropriate Public Education (FAPE) that the child receives in the Least Restrictive Environment (LRE). IDEA and the associated regulations emphasize the requirement to educate children with disabilities in regular classes 
with their nondisabled peers.

IDEA states that the FAPE needs to be available to all children between the ages of 3 and 21. But when parents and a public agency disagree about the availability of appropriate programs for the child and when there is a disagreement about financial reimbursement, this disagreement goes before the courts resulting in case laws. The general language of FAPE has resulted in several case laws that have provided more guidance into the interpretation about conditions under which FAPE prevails. For example case laws have been related to when schools cannot expel students for behaviors related to their handicaps and under what circumstances parents can be reimbursed for the cost of a private education for a child qualified to receive special education services (Wright \& Wright, 2007).

The lack of clarity about language related to FAPE also applies to LRE. What is accepted as LRE for one child may or may not be LRE for another child. The Individual Education Program (IEP) team, comprised of educators, parents and others invited to the team makes the decision about how to educate the child among typically developing children to the maximum extent appropriate. IDEA also requires that a range of placements be available. In addition to instruction in general education, other options for consideration include: special classes, special schools, home instruction, and instruction in hospitals and institutions. Then the IEP team must decide which one of these settings is the LRE for the child. According to Peter Wright and Pamela Wright (2007), "the Act [IDEA] and regulations recognize that IEP teams must make individualized decisions about the special education ... IDEA's strong preference that, to the maximum extent appropriate, children with disabilities be educated in regular classes with their nondisabled peers with appropriate supplementary aids and services" (p. 209).

IDEA has proven to be a major legislation having a large influence on the government's work on providing education to young children. However, there have been many case laws that have further interpreted the legislation. While IDEA helps pave the road to inclusive practices, the interpretation of the law has led to the greatest conflict between parents and schools.. Courts have helped to define what FAPE is, through the passage of case laws that have emerged. For example, in Board of Education $v$. Rowley $^{1}$, the U.S. Supreme Court ruled that IDEA does not require states to develop IEPs that 'maximize the potential of handicapped children.' Another case, Walczak v. Florida Union Free School District in 1998 asserts that children are not entitled to the best education that money can buy; they are only entitled to an appropriate education. Since there is no clear definition provided on what an 'educational benefit' is, this too has been further defined through case laws. A number of courts have struggled with the question of how much progress is sufficient, yet the standards are still somewhat vague. For example, case laws have better defined areas such as 'educational benefit' in N.R. v. Kingwood Township', and 'mainstreaming' in Florence County School District IV v. Shannon Carter. ${ }^{3}$

\section{No Child Left Behind}

In 2002, Congress passed the No Child Left Behind (NCLB), a federal policy to ensure that all students meet federal and state academic standards. For those schools and/or students who are not meeting the standard, a plan of remediation must be designed, implemented, and measured to ensure that academic success is being achieved. This policy was a modification from the Elementary and Secondary Education Act of 1965.

The NCLB is in high debate due to the lack of funds to support schools to provide such provisions. Over the past couple of years, the decrease in federal funding has left many to believe that this has become a failed law. In a recent article, Regina Umpstead (2008) questions whether the NCLB is an unfunded mandate or a promotion of federal educational ideals. Umpstead found that it is not an unfunded mandate when the federal use of spending power is taken into 
consideration: "In Article 1, section 8, clause 1 of the U.S. Constitution, in a manner that has gradually expanded its role in setting education policy by offering states federal dollars in exchange for compliance with the conditions specified in the relevant laws, such as the Individuals with Disabilities Education Act 210 and the Elementary and secondary Education Act 211" (p. 36). Therefore, Umpstead contends that the NCLB and the IDEA are not unfunded mandates. Even though the NCLB policy has caused an immense level of controversy in the educational system, it does prove to be a promotion of federal educational ideals. The government is not trying to raise the level of academic performance for students, but to assist with the implementation of standards, IEP, assessments, and accountability systems.

\section{State Initiatives and Policies}

\section{Achieving Indicators of the Federal Law and Regulations}

Both IDEA and NCLB have had an accountability reach to early childhood practices in the states. These federal legislations have set expectations for states to report information about outcomes desired from both legislations. Under IDEA, states have been required to develop a State Performance Plan ${ }^{4}$ around 20 indicators. Several of the indicators directly relate to early childhood inclusion. In particular, Indicator 6-Preschool LRE involves physical inclusion. It is defined as "percent of preschool children with IEPs who received special education and related services in settings with typically developing peers." The recent numbers, $53.38 \%$ for this indicator, for example in Michigan, (Michigan Annual Performance Report, 2005/2006) would suggest that there is much more to be done to support more students in inclusive learning situations. This indicator in Michigan has long been a standing issue as Michigan was one of the first states in the United States to have a birth to five years old mandate, prior to any federal special education laws.

Another indicator from the State Performance Plan is Indicator 8-Facilitated Parent Involvement. This indicator addresses the importance of parental involvement and is measured by "percent of parents with a child receiving special education services who report that schools facilitated parent involvement as a means of improving services and results for children with disabilities." Since parent involvement is a central component to supporting implementation of early childhood inclusion, this type of accountability might be helpful in promoting the elements of good practice for inclusion.

The consequence for not achieving the goals of any of the two indicators is having federal funds taken away. However, whether these consequences are implemented is yet to be determined.

\section{Insufficiency of Policies to Promote Early Childhood Inclusion: Beyond the Federal and State Levels}

Although field initiated training among early childhood program providers is beginning to receive some state and national attention, there continues to be an absence of how inclusion is disseminated. While federal and state policies have included language supportive of inclusion for young children with disabilities, they have been insufficient to actualize inclusion for children with disabilities. Therefore, implementation of inclusive early education requires support from areas beyond the policies at the federal and state levels and consensus on a vision of inclusion should be achieved by all stakeholders. Only when the local and individual areas work towards achieving student outcomes can inclusion occur (Salisbury, 1991).

\section{Personnel Preparation}

Knowledge, beliefs, and practices (Salisbury, 1991) 
are central to implementation of early childhood inclusion. The rationale often posed is that education will provide the necessary knowledge to inform practices and also influence beliefs. Traditional personnel preparation for early childhood education and programming lack education and training centered on early childhood inclusion practices (Perner \& Porter, 2000; Smith \& Smith, 2000). Thus teacher education programs and specializations such as speech therapy, occupational therapy, and school psychology are designed to inform critical personnel about ideas and skills. These programs have gone through some recent changes to reflect the policies at state and federal levels on 'qualified staff.' Through a professional certification process, knowledge and skills can be increased. However, the duality characterizing the existing education of special and general educators continues to influence the sustained duality of knowledge and skills of early childhood educators (Mungai \& Thornburg, 2005).

Beliefs and practices remain elusive. Cook's (2001) research on educators revealed that in the current high-stakes testing and requirement for accountability, the goal for teachers often is to have the largest group reach the highest level of achievement possible. While teachers may favor inclusion in the abstract, they tend to perceive typical students as individuals leading the achievement of the high-stakes demands of the larger environment. Thus students with disabilities are perceived as taking time and resources away from work that needs to be in place to achieve the high demands of showing student achievement.

\section{Importance of Curriculum}

The ideal vision of society is the integration of policy and practice. Federal and state laws are enforced, but how they are implemented into the educational system remains a question for educators. Current research for effective teaching practices is developing in the education field, especially for classroom inclusion, but it is educator's job to implement it into the individual child's curriculum. All children have different needs, whether the child is categorized as special needs or not. Teachers need to be able to speak and communicate to children on their own individual level. No child is the same.

\section{Parental Involvement}

At the local levels as well as state levels, parents have played a role in promoting inclusion. Here are a few examples. Parents committed to promoting inclusive education for children have organized in Michigan. Two organizational examples are The West Michigan Inclusion Network ${ }^{5}$, a non-profit organization, and Education for All a network of local parents who are advocating for inclusive practices in the school districts. The West Michigan Inclusive Network was formed by parents of students with disabilities to provide education and support to other parents, educators, and other interested people who want to have children with disabilities learning in inclusive settings. The board of directors is currently comprised of parents, general and special educators, and people with disabilities. The Network sponsors a yearly conference on inclusion. Education for All, by contrast, began as demonstration project funded by the Michigan Developmental Disabilities Council to promote a grass roots level approach to parents organizing to promote inclusive practices. Through a parent led initiative, with the infrastructure support of Michigan United Cerebral Palsy, a network of parents across the state with interest in inclusion was formed.

\section{Examples of Local Implementation of Inclusion}

Sometimes, local providers take the ideas based on the policies and implement successful inclusive practices. Two examples are provided below to depict this type of initiative.

Children's School for Early Development. Advocacy organizations have played an active role in promoting inclusive practices. One example is the Children's School for Early Development sponsored by the 
Westchester ARC. This School collaborates with community early childhood settings to promote inclusion and have graduated over 500 students since 1994.

HEARTS program. In 2003, based on the LRE and the mandate of the IDEA, a program was developed to include children with disabilities in art education. This program was titled, Human Empowerment through the Arts (HEARTS). Keifer-Boyd and Kraft (2003) established this program to decrease the level of anxiety for working along side of a person with a disability. They found that prolonged interaction enabled the art students to develop a relationship and view the children with disabilities as people with likes and dislikes (Keifer-Boyd \& Kraft, 2003).

\section{Other Factors Mediating the Pathway to Inclusion}

The literature on adoption of innovations in educational settings provides research that identifies conditions and factors influencing adoption of new ideas and programs (Lieber et al., 2000). McLaughlin (1990) examined four federally funded programs involving changes in school districts. The findings revealed that while federal policies appear to prompt the districts to begin the change process, change occurred when the leadership in the districts showed a commitment to change and took an incremental process of change as a strategy rather than implementing change throughout the district. Other factors included teachers participating in decision making, having opportunities to observe others implementing change, having classroom assistance and accessing individualized training. Fullan (1991) identified other factors such as the role of the external agent of change who assisted districts in designing a plan of change, community support, and having access to opportunities for attending conferences and meetings where new ideas can be shared to be brought back to the districts.

Specifically, for change to occur in preschool programs, Peck and his colleagues identified factors related to adoption of inclusion for preschoolers through a qualitative study looking at local implementations (Peck, Furman, \& Helmstetter, 1993). The specific factors that Peck and colleagues found were context, process, and outcome. Within the context factor it was important to have an agreement of goals and values between general educators and those interested in social integration. The second context factor is the degree of cooperation and mutual respect between child development and special education staff. The first process factor is the degree of collaboration and engagement in the design and decision making for the program. The second process factor is the compatibility between the design of special education instruction and the exciting routines of the child development setting. Finally, conflict was a common outcome factor for programs that cease to exist. The conflict is about control of time and activities for children. Surviving programs involved professionals that provide positive collaborations and positive problem solving strategies. The results of this study highlight the importance of communication and negotiation for the success of inclusion efforts, but do not minimize the technical aspect of integration.

\section{Universal Education}

Some educators and parents are working on the approach of inclusion to be that of creating and supporting universal education. For example, on October 2005, the State Board of Education in Michigan approved the Vision and Principles of universal education as a framework and foundation for policy development by the State Board, the Department of Education, and local and intermediate school districts. The principles of universal education described reflect the beliefs that each person deserves and needs a concerned, accepting educational community that values diversity and provides a comprehensive system of individual supports from birth to adulthood. The principles involve broad- 
based working partnerships to remove barriers that interfere or prohibit access to the range of learning opportunities. They recognize the key role families and primary caregivers play and their contribution to the development and education of children. The ideas around universal education evolved from years of effort among educators and parents working towards promoting inclusion.

\section{Discussion}

Inclusive early childhood education in the United States has been supported through policies, particularly IDEA, ADA and NCLB at the federal level. Inclusion is not mentioned, but the laws specifically state that schools are required to provide free and appropriate public education in the least restrictive environment.

The recent reach of these federal guidelines to state departments of education to create State Performance Plans addressing the states progress and setting goals for each of the indicators, more clearly sets accountability about early childhood physical inclusion and the involvement of parents in early childhood education. The dynamic process of defining words used in FAPE and LRE, two major components involved with inclusion, have provided for a number of case laws that further define the intentions of the legislation. While policies help to provide some framework nationally upon which to build practice, they are insufficient to fully implement inclusionary practices for young children.

The pathway to successful and widespread implementation of early childhood inclusion still has many barriers, remains uncertain, and yet is filled with opportunities. The process is complex and requires coordinated work at all levels-federal, state, local-along with stakeholder groups (families, teachers, administrators, and policymakers). Issues, such as funding, staffing, or quality continue to be barriers. On the other hand, when people in programs or at the local level share a common vision about and attitudes supportive of inclusion frame, collaborative relationships, and the motivation to problem-solve, inclusive early childhood settings will be allowed to emerge.

For the immediate future, work at all levels in our society needs to continue. More research needs to continue to inform inclusive practices in early childhood settings. Higher educational institutions need to more fully examine their obligations towards preparing teachers to have the philosophy and skills for implementing inclusive practices in the educational settings. One of the skills, working with diverse parents, begs for attention. Learning to partner with families/parents is a critical skill. Perhaps the idea of universal education needs to be examined in a more intentional way, as courses are developed. Policymakers need to think about the long-term funding issue. States will need to solve some of the discrete levels of program funding, which may mean disentangling current policies of funding education to more easily implement early childhood education.

Certification bodies will need to address what qualifications best serve young children, including children with disabilities in early childhood settings. Educators and administrators need to have a perspective supportive of inclusion. In addition, they need skills to implement inclusive practices. The bifurcated teacher preparation of special educators and general educators further deter teachers from obtaining the knowledge and perspective to support inclusion for these young children. On the other hand, professional associations like NAEYC can play a strong role in providing professionals with the expectations, lens and skills to provide inclusive education.

Finally, it is essential that support for parents of children with disabilities be given in order to assist them in understanding current inclusion policies and practices and to give them available options for including their child(ren). Parents can play a 
significant role in advocacy through knowledge about their rights under the law, and the parent training and information centers across the country funded under IDEA provide a good resource for parents to build their knowledge. Parents can organize and increase the opportunities for young children to learn in inclusive settings.

In the long range scope, the idea of developing a universal education framework might be useful. Given the diversity of learners in any given setting, this idea might provide greater ease in creating better learning environments for all young children. Accompanied by reforms in funding streams, universal education will promote positive learning outcomes for all children.

\section{References}

Buysse, V., \& Bailey, D. B. (1993). Behavioral and developmental outcomes in young children with disabilities in integrated and segregated settings: A review of comparative studies. Journal of Special Education, 26, 434-461.

Chugani, H. T., \& Bruer, J. (1998). Neuroscience and public policy. Public Health Reports, 113(6), 480482.

Cook, B. G. (2001). A comparison of teachers' attitudes toward their included students with mild and severe disabilities. The Journal of Special Education, 34(4), 203-213.

Diamond, K., \& Hestenes, L. (1994). Preschool children's understanding of disability: Experiences leading to the elaboration of the concept of hearing loss. Early Education and Development, 5, 301-309.

Diamond, K., \& Hestenes, L. (1996). Preschool children's conceptions of disabilities: The salience of disability in children's ideas about others. Topics in Early Childhood Special Education, 18, 118-128.

Diamond, K., Hestenes, L., \& O'Connor, C. (1994, April). Preschool children's understanding of disabilities. Paper presented at the American Educational Research Association Annual Conference, New Orleans.

Fullan, M. G. (1991). The new meaning of educational change (2nd ed.). New York: Teachers College Press.

Guralnick, M. J., (2001). A developmental systems model for early intervention. Infants and Young Children, 14(2), 1-18.

Keifer-Boyd, K., \& Kraft, L. M. (2003). Inclusion policy in practice. Art Education, 56(6), 46-53.

Lieber, J., Hanson, M. J., Beckman, P. J., Odom, S. L., Horn, E., \& Woley, R. (2000). Key influences on the initiation and implementation of inclusive preschool programs. Exceptional Children, 67(1), 83-98.

McLaughlin, M. W. (1990). The rand change agent study revisited: Macro perspectives and micro realities. Educational Researcher, 19(9), 11-16.

Michigan Annual Performance Report (2005/06). Michigan's State Performance Plan: Indicator 6. Lansing, MI: Michigan Department of Education.

Mungai, A., \& Thornburg, D. (2005). Rethinking our policy and practice. In A. Mungai \& E. Kogan (eds.), Pathways to inclusion: Voices from the field (pp. 47-62). Oxford, UK: University Press of America, Inc.

Odom, S. L. (2000). Preschool inclusion: What we know and where we go from here. Topics in Early Childhood Special Education, 20(1), 20-27.

Odom, S.L., \& Diamond, K.E. (1998). Inclusion of young children with special needs in early childhood education: The research base. Early Childhood Research Quarterly, 13, 3-25.

Peck, C., Carlson, P., \& Helmstetter, E. (1992). Parent and teacher perception of outcomes for typically developing children enrolled in integrated early childhood programs: A statewide survey. Journal of Early Intervention, 16, 53-63.

Peck, C. A., Furman, G. C., \& Helmstetter, E. (1993). Integrated early childhood programs: Research on implementation of change in organizational contexts. In C. A. Peck, S. L. Odom, \& D. D. 
Bricker (Eds.), Integrating young children with disabilities into community programs (pp. 187-205). Baltimore, MD: Paul H. Brookes.

Perner, D., \& Porter, G. L. (2000). Creating inclusive schools: Changing roles and strategies. In A. Hilton (Ed.), Best practices in the special education of students with mental retardation. Austin, TX: ProEd.

Salisbury, C. L. (1991). Mainstreaming during the early childhood years. Exceptional Children, 58(2), 146-155.

Schwartz, I. S., Sandall, S. R., Odom, S. L., Horn, E., \& Beckman, P. J. (2002). I know it when I see it: In search of a common definition of inclusion. In S. L. Odom (ed.) Widening the Circle. Including Children with Disabilities in Preschool Programs. New York: Teacher's College Press.

Schweinhart, L. J., Montie, J., Xiang, Z., Barnett, W. S., Belfield, C. R., \& Nores, M.(2005). Lifetime effects: The High/Scope Perry Preschool study through age 40. Ypsilanti, MI: High/Scope Press.

Skiba, R. J., Simmons, A. B., Ritter, S., Gibb, A. C., Rausch, M. K., Cuadrado, J., et al. (2008). Achieving equity in special education: History, status, and current challenges. Exceptional Children, 74(3), 264-288.

Smith, M. K., \& Smith, K. E. (2000). "I believe in inclusion, but-": Regular education early childhood teachers' perceptions of successful inclusion. Journal of Research in Childhood Education, 14(2), 161-180.

Umpstead, R. R. (2008). The no child left behind act: Is it an unfunded mandate or a promotion of federal education ideals? Journal of Law and Education, 37(2), 193-229.

Wolery, M., \& Wilbers, J. (Eds.). (1994). Including children with special needs in early childhood programs. Washington, DC: National Association for the Education of Young Children.

Wright, P., \& Wright, P. (2007). Wrightslaw: Special education law (2nd ed.). Hartfield, VA: Harbor House Law Press, Inc.

\section{Notes}

${ }^{1}$ Board of Education v. Rowley, 458 U.S. at 189

${ }^{2}$ U.S. Court of Appeals for the Third Circuit (2000)

3 U.S. Court of Appeals for the Fourth Circuit (1991)

${ }^{4} 20$ U.S.C. 1416 Sec. 616(b)(1) of the IDEA

${ }^{5}$ See www.wmin.org 